
the Philosophy of Religion 74: 77-98.

Van Bavel, J. J., D. J. Packer, and W. A. Cunningham. 2008. The neural substrates of ingroup bias. Psychological Science 19(11): 1131-1139.

Williams, P. A. 2001. Doing without Adam and Eve: Sociobiology and original sin. Minneapolis, MN: Fortress Press.

Xu, X., X. Zuo, X. Wang, and S. Han. 2009. Do you feel my pain? Racial group membership modulates empathic neural responses. The Journal of Neuroscience 29(26): 8525-8529.

\section{The Explanatory Challenge of Religious Diversity}

\author{
Jason Marsh and Jon Marsh
}

\section{Introduction}

Confronted with the world's many religious traditions, many people have felt pressed to ask the following question: how can one know that any particular religious outlook is true, given the existence of so many apparently conflicting religious outlooks? This way of interpreting the challenge of religious diversity is extremely common. It captivated Joseph Smith, for instance, and helped to spark the Latter Day Saints movement in nineteenth-century America. Troubled by the seemingly endless debate between different religious groups, Smith asked: "What is to be done? Who of all these parties are right; or, are they all wrong together? If any one of them be right, which is it, and how shall I know it?" $(1902,4){ }^{1}$

Smith's questions, though well known outside of the academy, have also motivated the main philosophical challenges from religious diversity. For instance, there is the contingency challenge, which has been said to undermine religious knowledge. As John Hick once put it, "someone born into a devout Muslim family in Pakistan is very likely to be a Muslim, someone born into a devout Hindu family in India to be a Hindu, someone born into a devout Christian family in Spain or Mexico to be a Catholic Christian; and so on (1997, 281)." There is also the challenge from peer disagreement, according to which the apparent reality of epistemic peers (i.e., equally honest and capable seekers of truth) from diverse faith traditions supports religious skepticism (Feldman 2007). Finally, there is the probabilistic challenge from diversity. According to this challenge, even if one particular religious tradition could be shown to be more probable than any of its competitors, in a one by one comparison, the 
combined probability of the competitors will still render it improbable, overall (Schellenberg 1997).

Such challenges can induce anxiety in believers, to be sure. But there is a growing sense among epistemologists that they all fail, in part because they rest on principles that, if endorsed, would create skeptical worries for many nonreligious beliefs (Plantinga 2000, ch 13; Kelly 2005; Bogardus 2013). Although we shall not rehearse these criticisms in detail here, many of our nonreligious beliefs are contingently held, rejected by apparent peers, and probabilistically challenged. ${ }^{2}$ In light of that, and given the widespread sense that pervasive religious diversity really ought to pose a special challenge to religion, we wish to generate a diversity challenge that does not amount to a general recipe for skepticism. We think that such a challenge can be formulated, and that it provides a partial answer to a charge, raised by Peter van Inwagen (2010), that people often hold religious beliefs to stricter evidential standards than other kinds of beliefs, such as political or moral beliefs. Our task will be to explore this challenge.

\section{The explanatory challenge}

Like ancient formulations of the problem of evil, the challenge we have in mind starts out as a question:

Explanatory Challenge: Why, if some particular theistic outlook is true, and if it's urgent that everyone believes that outlook, are there so many competing religions in the first place?

In contrast to the epistemological challenges mentioned earlier, the explanatory challenge invites reflection on the origins of diversity. This is of philosophical interest because it turns out that reflection on the origins of diversity is an effective way of uncovering an important tension in the beliefs of many theists-one that has less connection to Smith's questions and more affinities with hiddenness. arguments. ${ }^{3}$ Our first task will be to say something about what this tension is. Our second task will be to argue that this tension, though already notable in its own right, is harder to resolve in light of recent scientific accounts of religion. ${ }^{4}$ We close by considering how critics might respond to our claims. By this point, it should be clear that our goal is not to provide a universal defeater for anyone's theistic beliefs, but to raise what seems to us an important, interesting, and comparatively neglected challenge facing many theists.

\section{The scope of the challenge}

Let us begin by clarifying what we are not claiming. We are not claiming that the explanatory challenge arises for everyone. That is to say, our challenge does not rest on the following general principle: for any belief $\mathrm{P}$, if $\mathrm{P}$ is controversial and if it is urgent that people affirm $P$, then there is an epistemic problem in affirming $P$. This principle is implausible and would only invite the kind of general skepticism that we are seeking to avoid here. After all, take the belief that "humans are largely responsible for climate change" and the belief that "vaccines should be given to children." These beliefs are controversial, at least on the street, and it is urgent that people affirm them, if they are true. Yet, these factors alone do not count against holding them.

Put another way, the explanatory challenge is designed only for those with rather particular background beliefs about God and humanity. Not every person or even every religious person will hold these beliefs. In fact, not every theist will. For instance, those from nontheistic religious traditions, pluralists, nonrealists, or those who are highly apophatic in their orientation, may not face the explanatory challenge; nor will those who conceive of God as highly limited or highly impersonal. In addition, theists who think that God values diversity of opinion more than truth, ${ }^{5}$ or simply does not care about what people believe, or does not really want everyone to experience salvation (in the sense of deep, and normally everlasting, union with God) will not face the problem. On the other hand, many theists, we are tempted to say the majority of the world's theists, will reject all such claims as unorthodox and will face the challenge.

For instance, many theists are truth exclusivists who affirm that there is a single, uniquely valuable, theistic tradition in the world that by far best approximates the truth about the divine and humanity's place in the world. Some of these theists are further doxastic exclusivists who think that believing the right things about God and religion is at least very typically required for salvation. ${ }^{6}$ The explanatory challenge is intended for theists who hold at least one form of exclusivism and who conceive God to be a perfect being, with no limitations in knowledge, power, or love. It is further intended for those who understand God's love to mean that God wants everyone to flourish, religiously speaking, not just in the hereafter, but also in the present. For such persons, although it may be crucial to value all people and cultures, and to live together in peace, it will be difficult to equally value all ideas about the divine. ${ }^{7}$

Unsurprisingly, doxastic exclusivists will face the most difficult explanatory challenge, given their claims about the eternal fate of nonbelievers. But it is 
less often appreciated that even those truth exclusivists who reject doxastic exclusivism as narrow-minded still face a problem here. One reason for this concerns what is truly valuable in a theistic world. As advocates of so-called hiddenness arguments have long pointed out, if a personal God exists, then an explicit divine-human relationship in this life is highly valuable in its own right, even if no one's future salvation is on the line (Schellenberg 1993). As such, it seems plausible to think that a loving God would seek out such a relationship with everyone during their lives and would only permit resistant forms of nonbelief or disbelief in God.

This claim about the value of generic theistic belief is only half the story, however. Although standard hiddenness arguments overlook the point, many theists claim that their particular religious tradition has many unique benefits to offer the world, doxastic and otherwise. For instance, Roman Catholics are increasingly likely to acknowledge that those from other faith traditions, and perhaps even atheists, can experience salvation and can have implicit faith. They will sometimes even grant that Catholics can learn some things about the divine from people in other traditions. But these same Catholics will very often think that there are serious all things considered advantages to being Catholic, which offers the benefits of sacramental life, a unique degree of theological knowledge, and communion with the saints.

It is not just traditional Catholics who think this way. Probably most major theistic traditions (with some possible exceptions) ${ }^{8}$ have claimed to offer something uniquely valuable to the world, beginning with the truth about the most important matters in the universe. The question that such persons face is this: why would God permit so much diversity if this excludes so many from the temporal and/or eternal benefits mentioned above? True, perhaps some disagreement, say on more peripheral matters within a tradition, is inevitable. We also must not forget that religious traditions do converge on certain ideas. ${ }^{9}$ Even so, why so much disagreement even on the core issues? Why have so many extremely populated, and largely incompatible, religious traditions emerged, including African traditional religions, Buddhism, Chinese traditional religions, Christianity, Hinduism, Islam, Jainism, Judaism, Native American religions, Sikhism, Spiritism, and Zoroastrianism?

\section{The explanatory challenge generates an internal tension}

We realize that many theists are willing to give answers to these questions and to offer theological explanations of diversity. For instance, in more conservative
Protestant circles, one often hears religious diversity explained by some combination of sin, the Fall, demonic influence in the world, or if you are in certain Calvinistic circles, the selective benevolence of God. ${ }^{10}$ We will revisit some of these answers in due course and explore some challenges they face. In the meantime, we hope to underscore why the explanatory challenge is of philosophical interest. Briefly, the explanatory challenge does not merely seek to get theists to think more seriously about why religious diversity exists, it is also an invitation for them to better see a tension in their own beliefs. These beliefs are:

1. A perfect God exists and wants everyone to enjoy the many temporal and/or eternal benefits, doxastic and otherwise, that accompany explicit participation in the one true theistic religion. God is further willing to go to serious lengths to make this happen.

2. God permits multiple, competing, religious traditions to be extremely successful, and thus permits much, if not most, of the world's population to be deceived and to miss out on the temporal and/or eternal benefits in question.

The claim here is not that 1 and 2 are logically inconsistent. For instance, there may be a possible world in which both 1 and 2 are true and in fact one person, at least, has argued that versions of the following two claims are logically possible (Craig 1989).

3. No one who fails to believe the truth about revelation, on account of being raised in a mistaken religion, would have believed the truth even had they been raised elsewhere. Religious diversity thus disadvantages no one, even if doxastic exclusivism is true.

4. An unsurpassably loving God has good reasons for creating lots of people who God knew would not flourish.

We think that 3 is possible, in the broad logical sense, ${ }^{11}$ and although we are not confident about 4 , we will grant its possibility for the sake of argument. The relevant point is that logical consistency really does not tell us very much. This is because there can be serious tensions in one's beliefs, even if they fall short of logical inconsistencies or contradictions. These tensions can still remain important and troubling; they can also give one good, even if defeasible, reasons to revise one's beliefs. In fact, the present tension seems to be a textbook illustration of this point. If you affirm 1, you have reason to revise 2 and vice versa. If 1 is more fundamental in your web of belief than 2 , 
which in this case seems reasonable, then this clearly puts pressure on some feature of 2 , such as doxastic exclusivism.

Although we will not offer a theory of epistemic tensions or epistemic coherence here, we think the basic idea is easy to grasp when one sees it. For another example of an epistemic tension, consider the following two claims.

5. Jamie is a very good and very loving father.

6. Jamie refuses to talk to his children and will not even think about them.

Again, a logically possible story might be told to make both claims come out true (maybe the children have a condition such that talking to them or even thinking about them causes them severe harm). But, again, pointing this out hardly eliminates the tension.

Have we not overlooked something, however? In particular, might a skeptical theist insist that an omniscient God may well be aware of reasons entirely beyond our, often limited, imaginations for why 1 and 2 sit well together? Perhaps. But it is no less likely that God would have reasons, also entirely beyond our imaginations, for why 1 and 2 cannot hope to be reconciled..$^{12}$ We thus do not find that factoring in unknown possibilities eliminates a known tension. In saying this, we do not mean to rule out the possibility of mystery. In fact, we think that granting a tension is consistent with having considerable uncertainty about God's ways and so is consistent with so-called skeptical theism-at least, anyhow, when the latter approach is properly understood (Benton, Hawthorne and Isaacs 2016).

Actually, granting the tension seems to us like a fairly modest and reasonable thing to do. For instance, granting the tension does not require thinking that all theists have a full out defeater for any of their beliefs (where a universal defeater requires all theists to abandon some belief). Perhaps a few theists could even manage to avoid partial defeaters or requirements to hold their beliefs less firmly. Much will depend on specific circumstances of a believer and her background evidence and experiences. So the claim, again, is relatively modest. Even so, the claim is strong enough to be interesting. We think the tension we have raised, for instance, could reasonably lead many believers to suffer partial defeat for one or more of their beliefs. In addition, the tension could make it reasonable to give up doxastic exclusivism entirely, and perhaps more core beliefs, even if this is not absolutely required of them.

We realize that some may wish to deny even these weaker claims. But if one really thinks that 1 and 2 are not even in prima facie tension, and that serious diversity does not put even a little bit of pressure on the exclusivist to revise at least one of her beliefs, we confess that we have nothing more to say to such individuals. For those willing to concede the tension, on the other hand, we invite them to read on.

\section{Scientific accounts of religion}

Now that the original explanatory challenge is on the table, we hope to update it by incorporating insights from recent scientific accounts of religion. Here we have in mind cognitive and evolutionary approaches to the study of religion, which are discussed in the general area of Cognitive Science of Religion (CSR). Although CSR has troubled some theists, it is not intrinsically atheistic ${ }^{13}$ and, interestingly, has been endorsed by many notable theists, including Justin Barrett and Robert Audi.

So what does CSR tell us about religion? Although there is controversy within the field, most people in CSR seem to endorse a version of the naturalness of religion thesis. In very broad outline, this thesis claims that religious ideas are found throughout all known human cultures in no small part because humans are naturally predisposed to form and spread beliefs about supernatural agents. Although no one is born with religious beliefs, the basic idea is that with fairly minimal environmental stimuli, instruction, or effort, children in diverse environments tend to come to see the world in terms of some sort of supernatural agency, meaning, and design. Religion, so understood, is thus not merely a product of culture, as many suppose. It is a product of cognition, culture, and, whether directly or indirectly, evolution.

To be sure, there are different ways to put this claim about "naturalness" (Barrett 2010; McCauley and Cohen 2010). There are also interesting debates about how far a CSR framework can explain nontheistic traditions like Buddhism (Pyysiäinen 2003). Most agree, however, that our cognitive capacities and information processing biases constrain which religious ideas get formed and which become cultural. The more interesting challenge is to spell out these claims and to explain why religion arose to begin with. Here, three broad theoretical frameworks have emerged.

First, there is the by-product interpretation of religion, which is the standard model at the present time. According to this view, religion is an evolutionary accident. More accurately, religious ideas stem from domain-specific cognitive capacities that evolved in response to nonreligious adaptive challenges, and that fulfill nonreligious functions, but which generate religious ideas (Atran 
2002; Bloom 2007). Some of these capacities include agency detection abilities (which helps us to detect agents in our environments), theory of mind (which helps us to attribute beliefs and desires to perceived agents), and teleological reasoning (Evans 2000; Kelemen 2004; Lombrozo et al. 2007). Second, there is the evolutionary interpretation of religion. According to this view, religion exists in no small part because it gave groups a prosocial advantage (Sosis 2009; Schloss et al. 2010). Religion thus has adaptive significance. Finally, according to the hybrid perspective, the above two perspectives are not in competition and should be integrated. Perhaps religious belief starts out as a by-product. But once it gets going, it can help small groups to survive and to make the transition to large, cooperative, anonymous societies (Norenzayan 2013). If that is right, then by-products can later assume functions (Powell and Clarke 2012), suggesting an intricate interplay between genes and culture.

\section{How CSR explains religious diversity}

Interestingly, no matter which of the above three views one chooses, serious religious diversity seems almost inevitable. To see why, we admittedly need to engage in some storytelling-that is, speculative imaginings about what steps might have taken place in the past. We do not think that this is a bad thing, however. Science needs stories. If these stories lack sufficient evidence or explanatory payoff in the long run, or if they prove fundamentally misguided, we should reject them. Otherwise, we should refine and improve them over time. So what do the stories that are told in this context typically look like? Beginning with the by-product view, one often encounters stories like the following.

Story A: Approximately 40,000 years ago, a certain individual, walking in a forest at night, was suddenly stopped by a strange noise. The experience activated her agency detection capacity and she was suddenly filled with the sense that someone was watching her. Seeing no person or animal around, she quickly formed a belief in what later came to be called invisible forest spirits. She told her group about the experience and her testimony was well received. Her story further activated the theory of mind capacities of those present, leading to various questions such as Who are these spirits? What do they want? Are they our ancestors? Over time, a more refined interpretation of spirits developed.
Story B: Approximately 10,000 years ago, a different person lived in a stormy region near the fields. Following some violent cracks of lightening during a particularly bad storm, he formed the idea that a powerful being ruled the local skies and might be angry with him. He reported his experience back to his community and his testimony was accepted, eventually giving rise to more specific ideas and rituals, including a rain dance. Over time, and with the help of transmission errors, some of his descendants slowly switched from henotheism (the idea that each region has its own high god) to monotheism (the idea that there is but one God that rules the universe).

According to this by-product perspective, our agency detection systems and our theory of mind will bias us toward anthropomorphism (Guthrie 1993). Even so, the specific religious ideas that emerge and get transmitted, for instance the name of a spirit or what it wants, are highly context-dependent (Schloss et al. 2010, 626), ensuring a certain amount of diversity.

What about the evolutionary view of religion? Once again, nothing about this view predicts that different groups will have the same detailed religious beliefs or practices. Recall the core evolutionary idea. A belief in invisible, monitoring, agents helps to promote prosocial behavior in a group, which, in turn, creates a survival advantage. Since these supernatural watchers could have different identities (i.e., they could be witches, gods, or ancestor spirits etc.), and yet presumably play a similar functional role, we have no reason to expect only a belief in one kind of watcher to emerge. In fact, recent experimental evidence suggests that different supernatural agents can effectively play the watching role. In one influential study, being primed with ideas about Princess Alice was sufficient to inhibit cheating behavior in children (Piazza et al. 2011). As for the hybrid view, we do not see how this alternative would change the basic story we have been telling. It is still going to be true that people's religious ideas will seriously differ. In a word, if neither the by-product view nor the evolutionary view gives us reason to expect strong agreement on the details, combining them will not either.

\section{The updated explanatory challenge}

If the above claims about CSR are on track, then we can update the explanatory challenge as follows: 
Updated Explanatory Challenge: Why, if some particular theistic outlook is true, and if it's urgent that everyone believes that outlook, would God design the world in such a way that serious religious diversity naturally arises?

Whereas the original explanatory challenge asks why God would tolerate or permit so much diversity, the updated challenge asks why God would explicitly design the world to include it. This difference matters to the tension we have been exploring. Indeed, we shall now offer three reasons why the updated challenge, which makes use of CSR, is harder to answer than the original version.

Reason One: The updated explanatory challenge puts new pressure on many Abrahamic theists to give up what is perhaps the most commonly cited theological explanation of religious diversity, namely human free will and moral shortcomings.

Although not all theists are comfortable with it, many Abrahamic theists attribute religious diversity to sin and free will. This view, often held by ordinary believers, is also alive and kicking in much analytic philosophy of religion. Consider the following passage from Alvin Plantinga,

Were it not for sin and its effects, God's presence and glory would be as obvious and uncontroversial to us all as the presence of other minds, physical objects, and the past. Like any cognitive process, however, the sensus divinitatis can malfunction; as a result of sin, it has indeed been damaged. $(2000,177)$

To be fair, Plantinga does not assert that this view is true, only that it is true if his model of religious knowledge is true. Even so, he clearly believes it and notes that he is in good theological company. A similar view is held by some cognitive scientists. For instance, Justin Barrett makes an appeal to the Fall to answer the following very good question:

If ... God created humans so that they might enjoy a relationship with Him, why would God leave such important cognitive capacities to chance plus natural selection ... why do the documented conceptual biases only encourage belief in superhuman agents generally and not in one true, accurate god concept? ... why not hard-wire into our brains a fully formed belief in God? $(2009,97)$

Although Barrett does not develop this challenge, he briefly entertains the idea that somehow (we are never told exactly how), despite CSR and evolution, the "diversity of god concepts we see is a consequence of human error and not divine design" $(2009,97)$. Barrett is clearly referencing the Fall here and notes that a "sinful, fallen world" corrupts our concepts. ${ }^{14}$ This claim, like Plantinga's, does not sit well with CSR. In fact, it appears inconsistent with Barrett's own claim, made elsewhere, that "arguably the oldest and most widespread form of god concepts is the ancestor spirit or ghost, a type of afterlife belief" $(2007,775)$. On the latter view, belief in limited spirits and gods is the default state, with a belief in big gods coming later. Since all of this looks perfectly natural, CSR provides evidence for the following counterfactual: even if humans never behaved badly, there would still be pervasive religious diversity.

To clarify, in raising the above worry, we are not claiming that no diversity results from sin, given theism. For example, Augustine seems to have thought that God caused diversity at certain points to confuse the proud (De Doctrina Christiana II, 1-15). Perhaps the theist could call on this, and other kinds of spiritual resistance, to account for some religious diversity. But one would be hard pressed to explain all or most religious diversity this way. For one thing, there is the sheer amount of diversity that needs explaining: for any particular religious outlook, most of the world's population does not subscribe to it. For another thing, the typical causes of diversity look to be largely outside the scope of human agency. We do not typically choose our cultures, environments, beliefs, or our cognitive processes. In addition, there is the explanatory worry posed by an uneven distribution of religious ideas. The world's cultures are comparably prideful or sinful, and yet, the demographics of theism vary substantively over place (Maitzen 2006) and time (Marsh 2013), with early humans apparently lacking any theistic concepts. For the doxastic exclusivist, who thinks that one religion is uniquely true, the demographics of the target outlook become even more lopsided.

Some of the above considerations about the Fall and the demographics of theism have been noted by others, including Stephen Maitzen. Since Maitzen and others tend to entirely neglect the question of CSR and the origins of religion, however, they overlook cognitive and evolutionary explanations of the demographics of religious belief. This makes a difference. For Maitzen's challenge, aside from lacking a developed naturalistic explanation of the demographics of theism, ${ }^{15}$ leaves open whether God merely allows an uneven distribution of belief or causes it. By contrast, the updated explanatory challenge takes a clear stand on this matter. Indeed, the second reason why this updated challenge is more significant than more traditional versions draws upon the distinction between doing and allowing. 
Reason Two: The updated explanatory challenge suggests that God, given theism, does not merely allow serious religious diversity to emerge, but, to a large extent, causes it. This is because if theism is true, God is behind nature and responsible for creating brains and environments like ours through natural processes. But then serious religious diversity is largely the product of divine design.

Many theists think there is a moral difference between doing and allowing and will not be well positioned to reject reason two. Evidence for this claim may be found by looking at discussions of the problem of evil. It is widely thought by philosophers, including theists, that the problem of natural evil is harder to answer than the traditional versions. There are two reasons for this. First, the main classical theistic explanation of evil (free will) is no longer available. Second, it can be difficult not to attribute natural evil to divine action. We think CSR does for the explanatory challenge of religious diversity what natural evil does for the traditional challenge from evil. This is not to deny that there are ways of thinking about God, causation, and providence that dissolve the distinction between doing and allowing-for instance, occasionalism. But most theists seem to reject such views in part because they resist the idea that a perfect being would be so causally connected to evil actions.

To be clear, in raising this CSR-based worry that religious diversity is a natural feature of the world, we are not claiming our brains wholly determine our religious concepts, given CSR. As Michael Murray notes,

.... the mental tools identified by cognitive scientists [do not] give rise to these inconsistent [religious] beliefs all on their own. When environmental conditions stimulate HADD, Theory of Mind, memorability and transmissibility via minimal counterintuitiveness, etc., the outputs of these tools are still highly non-specific. HADD tells me there is "an agent"; my beliefs about what sorts of fauna inhabit these parts lead me to conclude that the agent is a bear or a tiger or the bogeyman .... no one doubts that divergent cultural traditions play an enormous role in giving religious concepts their specific contours. $(2009,172)$

We agree that environment matters to religious belief. In fact, it is the interplay between cognition and culture that, interestingly, poses much of the problem. For God, given theism, gets to decide how much of a role environment plays in the formation of religious belief and gets to decide how robust religious cognition is. To see the point, consider three possible worlds. In the first world, God hardwires some fairly detailed religious ideas into people's minds, such that people are practically born believing. In the second world, God does not make specific religious ideas innate, but ensures that every person with an open mind and an open heart acquires a detailed grasp of the one true religious tradition through experience. In the third world, God gives people general dispositions to form supernatural beliefs, but mostly leaves the details up to cultural evolution and environmental differences.

Now one could debate which of the first two worlds is preferable, given theistic exclusivism. For instance, some may wish to argue that world two is the preferable world because of the value of discovering important truths gradually. Others may prefer world two because they wonder whether universal agreement, owing to innate cognitive structure, would make some anxious about the possibility of universal deception or debunking. By contrast, others might insist that when it comes to the most urgent matters of the universe, at least (like certain moral ideas or a tendency to recognize one's parents at birth) that innate knowledge could be rather helpful. Failure to see this in the case of theism, goes the thought, is due to a status quo bias.

We are fully prepared to acknowledge that there could be a reasonable debate about the relative merits of worlds 1 and 2 . What seems less plausible to us is the suggestion that world 3 (i.e., the world we actually find ourselves in given theism and CSR) is preferable to both of these other worlds. For notice that the third world, under exclusivist assumptions, has an important disadvantage that the first two worlds lack. If God actualizes world three, substantive religious diversity, and by extension religious ambiguity, will naturally arise as a consequence of God's creative choice. In the case of doxastic exclusivism, many will miss out on salvation. In the case of truth exclusivism, many will walk in darkness during their time on earth.

The third and final sense in which CSR has normative or philosophical significance goes as follows:

Reason Three: Once we appreciate that some of the main competitors to theistic religion, namely naturalism, deism, and pluralism, do a better job of explaining the origins of religious diversity than Abrahamic theism, this might be thought to lend comparative support to these other views.

Reason three does not claim that Abrahamic religion, as opposed to say generic theism, makes the bare fact of religious diversity comparatively surprising. After all, Jewish, Christian, and Islamic scriptures are full of stories about religious differences-in fact these scriptures further acknowledge the reality of an uneven distribution of theistic belief. But then these traditions entail that there is lots of religious diversity (rendering the probability of such diversity 1). 
Given this way of reasoning about probability (Otte 2012), the bare existence of religious diversity, and even, pace Maitzen, the uneven distribution of theistic belief, cannot generate an empirical problem for Abrahamic faiths. For the reality of such diversity, if anything, confirms these views.

It is important to see that the above kind of reasoning, even if endorsed, does nothing to undermine reason three. For reason three is not about the bare fact of religious diversity, or its distribution, but about how diversity arises in the way that it does. Nothing in Abrahamic scriptures implies that religious diversity arises naturally in the way CSR suggests and on the time-scale it suggests. In fact, many theologians will insist, to the contrary, that religious diversity and the confusion it creates is unnatural. Many Christians and Jews, for instance, have thought that unbelief in a higher God is always foolish, sinful, and without excuse, given natural revelation. ${ }^{16}$ We appreciate that others will resist these interpretations. We also appreciate that exegesis is no easy task, and that many work hard to show that scripture sits well with science. Even so, the bare fact that there is a controversy within these major theistic traditions is significant. Since there is no similar controversy arising from naturalism, deism, or pluralism, ${ }^{17}$ this fact seems to support these other views.

\section{Objections}

We will now consider some objections to our arguments. We shall restrict our focus to just three.

Objection 1: Even if all of the scientific claims you discuss are true, which some might doubt, you still have not shown that religious diversity largely results from divine design. After all, in response to worries about evolution and natural evil, Alvin Plantinga has toyed with the idea that supernatural agents, besides God, could be responsible. He states that "Satan and his minions" might have been "permitted to play a role in the evolution of life on earth, steering it in the direction of predation, waste, and pain $(2011,59)$." Perhaps this idea could also be invoked to explain religious diversity. Here religious diversity will be natural all right, but it will be due to demonic agency and not to God.

So what should we make of the idea that demons have this kind of power over creation? Of course, the suggestion will seem absurd to those who do not believe in demons to begin with, as Planting appreciates, but that is not the right standard to adopt when considering an internal challenge. Even when we look at the matter internally, however, problems arise. Perhaps most notably, Plantinga's suggestion is difficult to square with the traditional idea that creation starts out good and indeed very good-on Plantinga's demonic evolutionary hypothesis that does not seem to be true..$^{18}$ In addition, that so many of Plantinga's theistic colleagues would reject his claim might give him further reason to question it.

A second possible objection, based on the work of Peter van Inwagen, also defends the idea of serious discontinuity in natural history and specifically human evolution.

Objection 2: The updated explanatory challenge, at least, fails since it remains epistemically possible that early humans were full-blown monotheists and that diversity arose because of sin. This is because it is epistemically possible, or true for all anyone knows, that the following story from van Inwagen is true: "for millions of years perhaps for thousands of millions of years, God guided the course of evolution so as eventually to produce certain very clever primates, the immediate predecessors of Homo sapiens. At some time in the last few hundred thousand years, the whole population of our pre-human ancestors formed a small breeding community - a few thousand or a few hundred or even a few score .... In the fullness of time, God took the members of this breeding group and miraculously raised them to rationality. That is, he gave them the gifts of language, abstract thought, and disinterested love-and, of course, the gift of free will... God ... also took them into a kind of mystical union with himself, the sort of union that Christians hope for in Heaven and call the Beatific Vision. But, somehow, in some way that must be mysterious to us, they were not content with this paradisal state. They abused the gift of free will and separated themselves from their union with God" $(2006,85-86)$. All of this, one might add, led to confusion about who God is and, for unknown reasons, the confusion became more pronounced in some regions than others.

There is much one could say here. Many biologists will claim population genetics, or other areas of science, rule out such possibilities. Many philosophers will think that the prior probability of van Inwagen's story is extremely low, even for ideal agnostics, and that it has more in common with skeptical scenarios than with a serious proposal. We will let van Inwagen fight these battles with others. A more basic problem with the current objection is that it still leaves the tension we raised basically intact. After all, van Inwagen would presumably admit that it is also epistemically possible-even for many theists-that the above story is false, and that diversity is indeed natural. But that alone is sufficient to establish the tension. Consider an analogy: knowing that it is epistemically possible that one does not have cancer is preferable to lacking this knowledge, to be sure. 
But one would surely still have reason to worry if the hypothesis that one had cancer became epistemically possible. In that case, one would want compelling evidence that one is cancer-free. We think something similar applies to our challenges. What goes under the name of a "defense" in discussions about the problem of evil is not enough to answer them.

There are naturally other objections that could be raised against our claims. But we shall take up only one more.

Objection 3: In focusing on Plantinga style theologies, your discussion leaves out other, often more positive, conceptions of the Fall and religious diversity. For instance, according to Irenaeus, humanity did not begin in a state of perfection, but in a less than fully mature state. As for humans, they gradually lost their innocence, but never were perfect to begin with. In fact, on this view, all of creation needs to gradually get better, which sits fine with CSR. Your focus on $\sin$ as a theological explanation of diversity, in addition, is not the whole story. For example, Augustine suggests that diversity results from (in addition to $\sin$ ) the sheer fact of human reality, where things as such are not easily graspable. There are also Islamic interpretations of diversity, according to which monotheistic diversity exists, in part, to motivate healthy moral competition among different monotheistic groups. Finally, maybe religious diversity exists, in part, because it helps people to engage with truth-which is basically the rabbinical model of truth in contestation.

We agree that there are many different possible religious explanations of diversity and wish we could spend more time canvasing different views. That said, we do not see a clear objection here. We never claimed that Plantinga's conception of the Fall and diversity is the only conception, only that it represents the dominant conception among philosophers of religion and more traditional theologians, particularly in the West. Showing that the dominant conception risks being disconfirmed seems significant to us. We suspect that the next most popular explanation of religious diversity, historically, is the Tower of Babel story (Seely 2001, 19). ${ }^{19}$ This explanation too is challenged by CSR. But we resisted the temptation to explore this, since fewer people read the story of Babel literally nowadays.

As for Irenaeus's views of creation and Fall, it is true that this may be compatible with CSR than more common views (De Cruz and De Smedt 2013). But it only restates the normative problem. After all, it is tempting to think that if diversity arises, under exclusivist assumptions, it should be owing to clear human moral shortcomings and not to divine design. ${ }^{20}$ The idea that God would make the world such that diversity naturally arises even though it is extremely bad for people's flourishing, which exclusivist views seem committed to, recall, just is our second tension. It is precisely because Irenaeus' view is more scientifically friendly, in other words, that it succumbs to our updated explanatory challenge. Of course, one could always revise one's theology in a pluralist direction to escape the tension, as John Hick seems to have done in his later years. But that would only be to concede the force of the explanatory challenge.

As for Augustine's idea that reality is not easily graspable by limited human beings, there is something to this. We also like the idea, shared by some Muslim scholars, that diversity can motivate healthy moral competition among monotheistic groups (Shah-Kazemi 92) ${ }^{21}$-and further find the rabbinical idea of truth in contestation interesting. ${ }^{22}$ It should be pretty clear that none of these answers gets us out of the pickle, however. Beginning with Augustine's claim about how hard it is to grasp reality, this claim leaves too much unexplained. Why is not everyone comparably in the dark about the divine, given human limitations? Why are some persons, and indeed some entire groups, so much more sensitive to the truth than others? And why does geography have so much to do with it, if a providential God exists and extends grace to all? Calling on our epistemic limitations does not explain these patterns. By contrast, many of these same patterns are to be expected given CSR.

As for the idea that diversity stirs up healthy moral competition, it is not obvious that monotheistic groups are outperforming other groups, morally-at least not by the kind of margin that would be required for this view to work. Besides, the view leaves wholly unexplained why nonmonotheistic religions exist. It will not work to expand the view so it becomes an explanation of all religious diversity either, since religious groups are not obviously more virtuous than secular groups: although they do better in some areas, like giving to charity, they do worse in others. The present view also raises a difficult question. Why would God design the world such that two very valuable outcomes-a detailed acceptance of revealed truth and moral motivation-are in competition in the first place?

The idea that there is truth in contestation too runs into empirical worries. For one thing, it can seem that most people do not contest the truth very much. Most seem rather content with their own outlooks and would literally rather not open the door to someone from a different tradition. As for the sizable minority who do enjoy a good religious discussion, these rarely convert to another tradition in response to their contestations (as is widely known, conversion across world religions is generally rare). All of this makes it hard to say that religious diversity exists, despite truth exclusivism, because it makes 
people more seriously engage with the truth or because it makes people come into contact with more religious truth in the long run. There are naturally other Jewish perspectives on diversity, including the idea that God, in some sense, "wanted Christianity and Islam to arise and spread, even if his reasons ... are hidden" (Shatz 2011, 372). But this, again, does not explain nonmonotheistic diversity; it further leaves monotheistic diversity rather mysterious.

In short, all the theological explanations of diversity of which we are aware either risk being falsified by CSR or other empirical factors, or do not actually help resolve the normative theological tension of why there should be so much diversity, again, given either form of exclusivism. We thus invite more discussion on these matters.

\section{Conclusion}

In conclusion, we have accomplished two things in this chapter. First, we explored a diversity challenge that does not create general skeptical problems for nonreligious beliefs. Second, we showed that CSR intensifies this challenge and so has philosophical significance for this reason. This last point about CSR is worth stressing because, although we did not mention it above, it is not just standard diversity challenges that threaten to generalize. Many philosophers have thought that standard debunking challenges to religious belief, based in CSR, also generalize. We were able to resist these two possible bases for skepticism.

Now some might have thought that CSR is, in reality, good news for theism. After all, this science seems to sit well with something that many theists will affirm: namely that religion is not merely a contingent cultural phenomenon, but a deep feature of human nature-and therefore something that a loving God could get behind. This tempting suggestion, popular among some evolutionary theists, ignores a more specific and more accurate way of describing what is going on, however.

Our explanatory challenge was not directed at supernaturalism in general, nor was it directed at every possible version of theism. Rather, it was directed at the actual beliefs of many theists when they say or imply that religious diversity is a highly unfortunate feature of the world, or when they claim that religious diversity is valuable but remain truth exclusivists. Although diversity no doubt makes the world a far more interesting place in many respects, relative to the particular beliefs we discussed, its existence is puzzling. If what is really part of human nature turns out to be a vague sense of the supernatural, a sense that can easily be taken in various directions, this more specific fact might be thought to be bad news for theists who are doxastic exclusivists, truth exclusivists, or both. If these claims are on track, then although some theists might find ways to preserve the rationality of their beliefs, despite the challenge we have raised (and recall we did not deny this), it is hard to say that CSR clearly has no prima facie philosophical significance for popular versions of theism or for claims commonly made by theists.

Finally, we should acknowledge that CSR, like any young science, could end up being completely wrongheaded. But our task here was not to defend CSR, only to discuss its implications on the assumption that its core claims are correct. To us, CSR's core claims look promising (much more so than traditional theological accounts of diversity) but still need further confirmation. Whatever happens with CSR, though, our stripped down explanatory challenge remains pressing and, in comparison to Joseph Smith's questions at least, neglected. It surely warrants future exploration. ${ }^{23}$

\section{Notes}

1 Smith eventually prayed for wisdom and claimed to discover the truth in a rather spectacular vision. Unfortunately, most who employ his method of belief formation are not so lucky and often come away with a very different outlook.

2 For instance, our moral and political beliefs are often contingent (we would believe them to be false had we been born elsewhere), controversial (many apparent peers reject them), and probabilistically challenged (the competition seems to stack against them). Now maybe the lesson here is that lots of our beliefs are in trouble on account of failing these various tests. But few epistemologists are willing to draw this more global lesson. Most prefer to see a problem with the diversity challenges.

3 We do not think the challenge here is the challenge from divine hiddenness, however, in part because nonbelief could arise, in principle, even if there was no diversity of religious opinion (for instance, everyone might be atheists or nontheistic Buddhists). Similarly, hiddenness arguments tend to focus on the value of belief in generic theism, as opposed to more specific beliefs and practices, and tend to say almost nothing about the origins of religion. We also do not think our challenge is reducible to the so-called soteriological problem of evil, since our challenge would go through even if all persons are saved. In any case, perhaps our challenge is best seen as a hybrid between a diversity challenge and a hiddenness argument, albeit one that introduces new features, as we shall see. In the end, we do not care too much about labels, however. 
4 At least, that is, for those who find these accounts plausible. We cannot defend entire scientific approaches here.

5 It is not enough to think that God values diversity to escape the problem; one must also show that diversity itself, or some good that diversity makes possible, is more valuable than true belief and what it makes possible.

6 Doxastic exclusivists will often grant that there is far more to religion than belief but will add that belief remains extremely important. Those who think good moral behavior is sufficient for salvation are not doxastic exclusivists, though they may still be truth exclusivists.

7 William Lane Craig, a well-known doxastic exclusivist, thus states: "compassion toward those in other world religions is therefore expressed, not in pretending that they are not lost... but by ... making every effort ... to communicate to them the life-giving message of salvation" (1989, 187-188).

8 This explains the many missionary and proselytizing efforts throughout history. There is the idea of Dawah in Islam and Christian evangelism. Some even argue that Hinduism can, despite initial appearances to the contrary, be seen as a missionary religion (Sharma 2011). Judaism is perhaps the most obvious counterexample here-and there are many historical, sociological, and religious reasons for this (Shatz 2011). Even so, if some traditional strand of Judaism were literally true, many non-Jews might have an interest in knowing this.

9 For example, some religions converge on monotheism, and many more converge on the golden rule.

10 We will say nothing about Calvinistic views in this chapter mainly because we are talking to theists who think God loves everyone and fully desires their salvation.

11 One of us once argued that a version of claim 3 could be seem minimally reasonable for Molinist theists who are also universalists about salvation (Marsh 2008). We do not endorse 3 as serious possibility, in part, because we do not like what it seems to imply about many nontheists. In any case, Craig's Molinist explanation of 3 , in rejecting universal salvation, raises even bigger worries.

12 This kind of point is often made by Paul Draper.

13 Some might worry that CSR is methodologically atheistic and claim that it simply begs the question against the theist for this reason. After all, it might be thought that the naturalistic approaches to religion leave no room for some groups to have received special miracles, moral instructions, and Holy Books from on high. In response: this objection, though understandable given how some scientists speak, is unfortunately misguided. For whatever particular scientists do or say, CSR can in principle allow that some miracles or revelation might have occurred, if the evidence favors this. The problem is that, even given this openness to the supernatural, much diversity remains. By the theist's own admission, then, miracles, revelation, and the testimony of the faithful have not been especially effective in eliminating diversity. But then pointing to methodological worries about science is a moot point.

14 He even adds that in the absence of human moral failure, "perhaps children would inevitably form a perfect concept of God" $(2009,97)$.

15 Maitzen notes briefly on two occasions that, on naturalistic explanations, "culture and politics alone" $(2006,185)$ determine and explain the demographics of theism. Though Maitzen's overall challenge is interesting, this strikes us as too simple.

16 Psalm 14 and Romans 1 have often been read this way, for example.

17 We have heard some reject this claim with the following counterfactual: if a perfect God did not exist, nothing would exist. We will resist the temptation to explain why we think this counterfactual, even if taken to be true, does not resolve our challenge.

18 We are indebted to John Greco for helping us to see this point.

19 Many Jewish and Christian thinkers, including Augustine, Luther, and Calvin, apparently understood the Tower of Babel to explain much cultural and linguistic diversity (Seely 2001, 19). We have heard some religious leaders invoke this same explanation to account for religious diversity.

20 This is not to say that "free will views" face no challenges, only that they face fewer challenges than divine causation views.

21 We are told that Quran 5:48 is commonly cited as evidence for this view.

22 Thanks to Sarah Coakley for drawing our attention to this rabbinical view.

23. We are grateful to Sarah Coakley, Helen De Cruz, John Greco, Jamie Schillinger, Corliss Swain, Charles Taliaferro, and to two anonymous referees for their feedback and questions. The ideas discussed here are ours and should not be assumed to reflect the views of any institutions with which we are affiliated.

\section{Bibliography}

Atran, S. 2002. In Gods We Trust. The Evolutionary Landscape of Religion. Oxford: Oxford University Press.

Augustine of Hippo. 1995. Augustine De doctrina Christiana. Oxford: Clarendon.

Barrett, J. L. 2007. Cognitive science of religion: What is it and why is it? Religious Compass 1(6): 768-786.

Barrett, J. L. 2009. Cognitive science, religion and theology. In M. Murray and J. Schloss, eds, The believing primate: Scientific, philosophical, and theological reflections on the origin of religion, 76-99. New York: Oxford University Press.

Barrett, J. L. 2010. The relative unnaturalness of atheism: On why Geertz and Markusson are both right and wrong. Religion 40: 169-172.

Benton, M. A., J. Hawthorne, and Y. Isaacs. 2016. Evil and evidence. In J. Kvanvig, eds, Oxford studies in philosophy of religion, vol. 7: 1-31. Oxford: Oxford University Press. 
Bloom, P. 2007. Religion is natural. Developmental Science 10: 147-151.

Bogardus, T. 2013. The problem of contingency for religious beliefs. Faith and Philosophy 30(4): 371-392.

Craig, L. W. 1989. "No other name": A middle knowledge perspective on the exclusivity of salvation through Christ. Faith and Philosophy 6: 172-188.

De Cruz, H. and J. De Smedt. 2013. Reformed and evolutionary epistemology and the noetic effects of sin. International Journal for Philosophy of Religion 74: 49-66.

Evans, E. M. 2000. Beyond scopes: Why creationism is here to stay. In P. L. Harris, C. N. Johnson, and K. S. Rosengren, eds, Imagining the impossible: Magical scientific, and religious thinking in children, 305-331. Cambridge: Cambridge University Press.

Feldman, R. 2007. Reasonable religious disagreements. In L. M. Antony, ed., Philosophers without Gods: Meditations on Atheism and the Secular Life, 194-214. New York: Oxford University Press.

Guthrie, S. 1993. Faces in the clouds: A new theory of religion. New York: Oxford University Press.

Hick, J. 1997. The epistemological challenge of religious pluralism. Faith and Philosophy 14: 277-286.

Kelemen, D. 2004. Are children "intuitive theists"?: Reasoning about purpose and design in nature. Psychological Science 15: 295-301.

Kelly, T. 2005. The epistemic significance of disagreement. In T. Gendler-Szabo and J. Hawthorne, eds, Oxford studies in epistemology, 167-196, Vol. 1. Oxford: Oxford University Press.

Lombrozo, T., D. Kelemen, and D. Zaitchik. 2007. Inferring design: Evidence of a preference for teleological explanations in patients with Alzheimer's disease. Psychological Science 11: 999-1006.

Maitzen, S. 2006. Divine hiddenness and the demographics of theism. Religious Studies 42: 177-191.

Marsh, J. 2008. Do the demographics of theistic belief disconfirm theism? A reply to Maitzen. Religious Studies 44: 465-471

Marsh, J. 2013. Darwin and the problem of natural nonbelief. The Monist 96: 349-376.

McCauley, R. N. and E. Cohen. 2010. Cognitive science and the naturalness of religion. Philosophy Compass 5: 779-792.

Murray, M. 2009. Scientific explanations of religion and the justification of religious belief. In M. Murray and J. Schloss, eds, The believing primate: Scientific, philosophical, and theological reflections on the origin of religion, 168-178. New York: Oxford University Press.

Norenzayan, A. 2013. Big gods: How religion transformed cooperation and conflict. Princeton, NJ: Princeton University Press.

Otte, Richard. 2012. Comparative confirmation and the problem of evil. In J. Chandler and V. S. Harrison, eds, Probability in the philosophy of religion, 127-143. Oxford: Oxford University Press.
Piazza, J., J. Bering, and G. Ingram. 2011. "Princess Alice is watching you": Children's belief in an invisible person inhibits cheating. Journal of Experimental Child Psychology 109: 311-320.

Plantinga, A. 2000. Warranted christian belief. Oxford: Oxford University Press.

Plantinga, A. 2011. Where the conflict really lies?: Science, religion, and naturalism. New York: Oxford University Press.

Powell, R. and S. Clarke. 2012. Religion as an evolutionary byproduct: A critique of the standard model. British Journal for Philosophy of Science 63: 457-486.

Pyysiäinen, I. 2003. Buddhism, religion, and the concept of "God". Numen 50(2): 147-171.

Schellenberg, J. L. 1993. Divine hiddenness and human reason. Ithaca, NY: Cornell University Press.

Schellenberg, J. L. 1997. Pluralism and probability. Religious Studies 33: 143-159.

Schloss, J., J. Barrett, and M. Murray. 2010. Looking past vs. overlooking cognitiveevolutionary accounts of religion: A response to Nathaniel Barrett. Journal of the American Academy of Religion 78(3): 622-628.

Seely, P. H. 2001. The date of the tower of Babel and some theological implications. Westminster Theological Journal 63: 15-38.

Shah-Kazemi, R. 2013. Beyond polemics and pluralism. The universal message of the Qur'an. In M. Hassan Khalil, eds, Between heaven and hell: Islam, salvation, and the fate of others, 87-105. New York: Oxford University Press.

Sharma, A. 2011. Hinduism as a missionary religion. Albany, NY: State University of New York Press.

Shatz, D. 2011. A Jewish perspective. In C. V. Meister, ed., The Oxford handbook of religious diversity, 365-380. New York: Oxford University Press.

Smith, J. 1902. History of Joseph Smith: The Prophet. Salt Lake City: Deseret News.

Sosis, R. 2009. The adaptationist-byproduct debate on the evolution of religion: Five misunderstandings of the adaptationist program. Journal of Cognition and Culture 9: 315-332.

van Inwagen, P. 2006. The problem of evil. Oxford: Oxford University Press.

van Inwagen, P. 2010. We're right. They're wrong. In R. Feldman and Ted. A. Warfield, eds, Disagreement, 10-28. Oxford: Oxford University Press. 